\title{
TIERRAS DE COMÚN REPARTIMIENTO Y PEQUEÑA PROPIEDAD EN SAN JUAN TEOTIHUACÁN, ESTADO DE MÉXICO, $1856-1940$
}

\author{
J. Edgar Mendoza García \\ Centro de Investigación y Estudios Superiores \\ en Antropología Social
}

\section{INTRODUCCIÓN}

Cegún los estudios regionales de las últimas décadas, la - ley general de desamortización de 25 de junio de 1856, mejor conocida como Ley Lerdo, decretó el fin de la propiedad corporativa de antiguo régimen y estableció la propiedad privada plena. Dicha legislación no sólo afectó los bienes de manos muertas de la Iglesia sino también las tierras comunales de los pueblos indígenas y mestizos que administraban los ayuntamientos. Sin embargo, hoy sabemos que la privatización de los diversos tipos de propiedad comunal fue un proceso confuso e inacabado, pues muchos pueblos lograron conservar sus propiedades colectivas por medio de distintos mecanismos legales e ilegales; desde la rebelión y el uso adecuado de la ley hasta la utilización de

Fecha de recepción: 23 de septiembre de 2015

Fecha de aceptación: 12 de julio de 2016 
prestanombres y sociedades agrícolas. ${ }^{1}$ Pero lo que más llama la atención es que incluso en algunas legislaciones estatales continuaron conservandose de manera ambigua estas formas de propiedad, por ejemplo, algunas leyes del estado de Oaxaca dejaron en poder de las agencias municipales "la administración de tierras comunales"; 2 algo similar también ocurrió en el Estado de México, donde en la nomenclatura oficial se conservó el término "tierras de común repartimiento" y "propios del ayuntamiento", pero que a la luz de la legislación liberal y el sistema fiscal adquirieron otras características. En este contexto, el presente artículo tiene el propósito de analizar la persistencia y el funcionamiento de las "tierras de común repartimiento", su vinculación con la pequeña propiedad privada y su uso en la nomenclatura fiscal y el sistema de propiedad del municipio de San Juan Teotihuacán en el Estado de México, en un largo periodo que va de mediados del siglo xix hasta la década de 1940, es decir, desde la reforma liberal hasta la reforma agraria mexicana. ¿Por qué continuaron denominándose tierras de común repartimiento las parcelas adjudicadas a los campesinos locales, si se supone que según la ley general deberían ser propiedad privada? ¿Por qué el municipio recibió las contribuciones en forma de censo redimible por este tipo de

\footnotetext{
${ }^{1}$ Para conocer la diversidad de respuestas de los pueblos a la desamortización de sus propiedades comunales, véase MARINO, "La desamortización de los pueblos"; Falcón, "Desamortización a ras de suelo"; CAMACHO, "De la desamortización a la reforma agraria"; SÁnchez Silva, La desamortización civil en Oaxaca; Velasco y García, Perfiles. Sobre los condueñazgos, Escobar OHMSTEde, "Los condueñazgos indígenas en las Huastecas"; Kourí, Un pueblo dividido.

2 Mendoza, Municipios, cofradías y tierras comunales, p. 107.
} 
propiedad? ¿Qué relación existe entre las tierras de común repartimiento del siglo xx y la pequeña propiedad privada?

A manera de hipótesis, considero que no sólo fueron razones de índole económica, sino también el conocimiento previo que tenían los campesinos sobre este tipo de propiedad, las que fomentaron la persistencia del término "tierras de común repartimiento” en el sistema fiscal de las municipalidades del Estado de México, pero tanto sus funciones como el estatuto jurídico de la propiedad eran diferentes a los que tuvieron antes de 1856. Desde fines del periodo colonial hasta mediados del siglo XIx, las tierras de común repartimiento eran las parcelas que se otorgaban a las familias para su sustento; se trataba de tierras del común, también llamadas tierras de comunidad, y que en general eran usufructuadas por las familias campesinas, es decir, mientras las cultivaran permanecían en sus manos y hasta las podían heredar o vender con la venia de las autoridades locales, pero en el fondo se vendía el usufructo pues la propiedad de la tierra continuaba en manos de la corporación. ${ }^{3}$ A cambio de estos derechos, los campesinos comuneros tenían que pagar el tributo y después la capitación, además de cumplir con sus obligaciones comunitarias, prestando servicios gratuitos en el gobierno civil o religioso; ${ }^{4}$ asimismo desempeñaban faenas y cooperaban con la escuela municipal, el sistema de cofradías y mayordomías. Sin embargo, el término resulta confuso porque después de 1856 continuaron denominándose de la misma forma, "tierras de común repartimiento", las parcelas que fueron adjudicadas en

\footnotetext{
3 Menegus, La Mixteca Baja, p. 163.

${ }^{4}$ Birrichaga, “Administración de tierras y bienes comunales”, p. 264.
} 
propiedad individual a los campesinos; así, mientras estos adjudicatarios beneficiados no cubrieran el monto total de su valor, tuvieron que pagar un censo a la tesorería municipal, y aun cuando se estableció el impuesto predial a fines del XIX se les continuó anotando de la misma forma hasta mediados del siglo $\mathrm{xx}$.

Cabe señalar que esta investigación se sustenta en el análisis del fondo de Tierras y Tesorería del Archivo Histórico Municipal de San Juan Teotihuacán, el Archivo Histórico del Agua y el Archivo General Agrario, así como en una bibliografía secundaria.

\section{ANTECEDENTES}

Desde el periodo colonial hasta principios del siglo xix la mayoría de los pueblos de indios del altiplano central y el sureste de México mantuvieron básicamente cuatro tipos de propiedad comunal: el fundo legal era el lugar donde se localizaban los edificios públicos y casas-solares de los habitantes, abarcaba 500 varas y después 600 , medidas desde el templo eclesiástico; los propios, eran terrenos que se rentaban y sus ganancias se destinaban a solventar los gastos municipales; los ejidos estaban constituidos por bosques y pastos de donde se obtenía leña, tequesquite y materiales de construcción; las tierras de común repartimiento, de parcialidad o comunidad, eran usufructuadas para la subsistencia familiar y eran las más parecidas al ideal liberal de la propiedad privada pues, aunque pertenecían a la corporación, estaban divididas desde hacía mucho entre las familias. ${ }^{5}$ Otros

${ }^{5}$ Mendieta, El problema agrario de México, pp. 38-51; Knowlton, "La 
estudiosos del tema agregan que dentro de los pueblos también existían tierras de santos o cofradías y además propiedades particulares de cacicazgos indígenas. ${ }^{6}$ Así, las diversas tierras funcionaron de acuerdo a las circunstancias económicas regionales, por ejemplo, si una tierra de propios dejaba de arrendarse se convertía en ejido o viceversa. Pero en otros casos se adaptaron a los sistemas de cultivo, como sucedió en Yucatán, donde fue difícil delimitar este tipo de propiedades comunales por la misma rotación de los cultivos en los montes. ${ }^{7}$ Por tanto, los efectos de la privatización sobre los distintos tipos de tierras comunales no fueron los mismos ni para los pueblos que los perdieron ni para los nuevos propietarios que las adquirieron.

La Constitución de Cádiz promovió el reparto individual de las tierras corporativas y aunque estas medidas no se pusieron en práctica, sentaron las bases para la desamortización en el periodo independiente. En 1824 el congreso mexiquense propuso que tanto los propios como las tierras del fundo legal y de repartimiento quedaran para el sostenimiento de los ayuntamientos. Así, a pesar de que intelectuales y legisladores como José María de Jáuregui, Ignacio Nájera y José María Luis Mora propugnaron por la propiedad individual, finalmente el Congreso del Estado de México consideró que la desamortización era inviable. ${ }^{8}$

individualización de la propiedad", p. 184; Menegus, "Ocoyoacac, una comunidad agraria en el siglo XIX”, pp. 151-152.

6 Birrichaga, "Administración de tierras y bienes comunales"; Mendoza, Municipios, cofradias y tierras.

7 OrTiz Yam, De milperos a henequeneros.

${ }^{8}$ Un debate más amplio sobre la posición y discusión de los diputados en torno de estos asuntos puede verse en BIRRICHAGA, "Imaginar el poder local”, pp. 208-219. 
En primer lugar, porque los vecinos no contaban con recursos para hacer que las pequeñas propiedades fueran productivas, y en segundo, porque los ayuntamientos carecían de recursos para solventar su administración y desarrollo. Por tanto, el gobierno estatal optó por dejar bajo el control del ayuntamiento las tierras que antes pertenecían a los pueblos de indios, otorgándole el derecho de cobrar una pequeña cuota de arrendamiento a los vecinos beneficiados en los repartimientos de terrenos. En palabras de Marino, lo que cambió era el pago de dicha cuota por el usufructo de tierras, que en definitiva era un reemplazo del tributo colonial. ${ }^{9}$

Otras leyes posteriores del Estado de México también dejaron en manos de la jurisdicción municipal la propiedad de las tierras comunales. Por ejemplo, el decreto de 9 de mayo de 1833, en su artículo 1a adjudicó “a los ayuntamientos para sus propios los terrenos realengos o baldíos, que existan en el territorio de sus municipalidades". Con ello, el gobierno municipal quedó como la instancia jurídica con facultad para administrar la propiedad de las tierras; el artículo $5^{\circ}$ es elocuente al respecto: "Los ayuntamientos con acuerdo del síndico, arrendarán los terrenos, dividiéndolos en porciones pequeñas para beneficiar a las distintas familias", ${ }^{10}$ así, al igual que la antigua república de indios, el ayuntamiento republicano del Estado de México siguió manejando y distribuyendo los terrenos a las familias, aunque ahora bajo la vigilancia de prefectos y subprefectos. ${ }^{11}$ De acuerdo con Molina Enríquez, con esta ley los

9 Marino, “La modernidad a juicio”, pp. 178-179.

10 Colección de decretos, 1850, decreto de 9 de mayo de 1833.

11 Sobre el papel de los prefectos y subprefectos véase Salinas, Los municipios en la formación del Estado de México, pp. 65-68. 
ayuntamientos del Estado de México fueron "los fideicomisarios del patrimonio municipal formados de los bienes asignados originariamente, acumulados y acrecidos sobre los cuales se encuentran incorporados los realengos y baldíos, y los llamados Bienes de común repartimiento". ${ }^{12}$

Dicho de otro modo, el ayuntamiento mantuvo el control sobre el reparto de las tierras municipales a cambio de un canon o censo desde antes de la desamortización. Asimismo, las tierras comunales y realengas fueron administradas como propios por los ayuntamientos. Durante las primeras décadas independientes, la debilidad de las finanzas municipales volvía impracticable la desamortización de las propiedades de los pueblos. ${ }^{13}$ Así que cuando se decretó la Ley Lerdo, los municipios y municipalidades del Estado de México contaban con una larga experiencia para administrar los terrenos y aprovecharon la oportunidad para seguir obteniendo ingresos fiscales.

Cabe mencionar que, en un estudio de principios del siglo xx, Molina Enríquez trató de esclarecer el término "tierras de común repartimiento" durante el periodo colonial, sin embargo, encontró pocas referencias e imprecisas sobre este tipo de propiedad, y más bien identificó que sólo se hacía referencia a los "repartimientos de tierras" que se efectuaban para dar cabida a nuevas familias, las cuales estaban diferenciadas del fundo legal y ejidos de los pueblos. Según Molina, tal concepto adquirió una connotación más clara a partir de la Ley Lerdo, principalmente en el Estado de México, donde el término "tierras de común

12 Molina, Breve estudio para la determinación jurídica, p. 46.

${ }^{13}$ Menegus, "La desamortización de los bienes comunales", pp. 293-296. 
repartimiento" se continuó utilizando para todas aquellas parcelas adjudicadas y que tenían el fin de cobrar un censo redimible en favor de las arcas municipales. ${ }^{14}$ Así no resulta extraño que los terrenos de común repartimiento que aparecen registrados en los archivos municipales con motivos fiscales en la segunda mitad del siglo xix y primeras décadas del xx sean en realidad todos aquellos terrenos usufructuados que estaban en poder de las familias antes de 1856 y que conforme a la Ley Lerdo fueron adjudicados a los comuneros y avecindados tanto indios como mestizos; es decir, en este concepto fiscal, ${ }^{15}$ se incluyeron los sitios solares del fundo legal, las tierras de parcialidad también llamadas de común repartimiento, e incluso, bajo este mismo rubro se inscribieron las tierras baldías que fueron privatizadas en pequeños y grandes lotes durante el porfiriato.

\section{LA LEY LERDO EN TEOTIHUACÁN}

A principios del siglo xx, Lucio Mendieta apuntó de manera contundente que la desamortización de la propiedad comunal en el valle de Teotihuacán fue desastrosa para los pueblos ya que la mayoría de los campesinos que se adjudicaron sus parcelas de común repartimiento muy pronto las vendieron a los hacendados y, por tanto, la pequeña propiedad era muy escasa en estos años. ${ }^{16}$ Sin embargo, un acercamiento a

${ }^{14}$ Molina, Breve estudio para la determinación jurídica, pp. 31-32.

${ }^{15}$ Carmen Salinas señala que tanto los propios como las tierras de común repartimiento formaron parte de una categoría fiscal en el Estado de México, es decir, se constituyeron en una contribución que iba a parar a las arcas municipales; Salinas, "Desamortización en Acambay", p. 149. ${ }^{16}$ Gamio, La población del valle de Teotibuacán, vol. 3, pp. 765-775. 
los archivos locales muestra que el proceso de privatización fue más complejo, y que si bien es cierto que muchos campesinos pobres vendieron sus parcelas de cultivo, no siempre lo hicieron con los hacendados sino principalmente con los rancheros, pequeños propietarios y caciques locales. De modo que aún después del reparto agrario, la pequeña propiedad tenía un peso significativo en el control del sistema de riego y la producción del valle, como veremos más adelante.

Aunque la Ley Lerdo de 25 de junio de 1856 vino a cambiar el sistema de propiedad en México y afectó la estructura de las corporaciones civiles, entre ellos los pueblos indígenas y los ayuntamientos, también hay que señalar que con la adjudicación de parcelas de común repartimiento el campesino comunero compró al ayuntamiento la parcela que previamente venía usufructuando en la república de indios. Según Margarita Menegus, la manera en que se llevó a cabo fue mediante la compra a censo redimible, es decir, el adjudicatario debía pagar cada año un censo o rédito de $6 \%$ sobre el valor de la propiedad adjudicada. ${ }^{17}$ Esto significó que mientras los campesinos no liquidaran el monto total del valor del terreno seguirían pagando por años este gravamen, asunto que convenía a los ayuntamientos porque recibían ingresos constantes, y esto fue precisamente lo que pasó en Teotihuacán y en otros municipios del Estado de México, que además quedaron bajo la supervisión de los jefes políticos.

En otras regiones los ayuntamientos tuvieron dificultades para cobrar las contribuciones a los adjudicatarios. Por

17 Menegus, La Mixteca Baja, p. 167. 
ejemplo, en el estado de Oaxaca, los municipios recaudaron muy poco por este rubro, quizá porque desde fines de la década de 1870 se estableció el Registro Público de la Propiedad y los pequeños propietarios registraron sus parcelas de cultivo y pagaron a dicha dependencia. ${ }^{18}$ En cambio, en el Estado de México, los adjudicatarios pagaron su censo y para fines del siglo XIX éste constituía el principal ingreso de la tesorería municipal. ${ }^{19}$ Aunque la contribución predial se decretó en 1861, sólo se cobró regularmente a partir de 1869. En un principio se cobraba una cuota de 7 al millar sobre el valor de las fincas rústicas y urbanas, en 1868 el censo bajó a 3\% como contribución a la tesorería municipal, ${ }^{20}$ y posteriormente fue en aumento hasta alcanzar el 10 al millar en 1879. En la década de 1870 se intentó elaborar un catastro, sin embargo fracasó y dichas medidas para gravar a la propiedad no se lograron sino en $1923 .{ }^{21}$ Así, mientras no había una institución estatal, el municipio continuó cobrando los réditos y la contribución predial sobre los llamados terrenos de común repartimiento.

En el caso de los pueblos y barrios del municipio de San Juan Teotihuacán, el proceso de privatización se inició cuando los campesinos comuneros acudieron a solicitar la adjudicación de sus terrenos de común repartimiento, pero también fueron los ayuntamientos quienes fomentaron el proceso pues estaban ansiosos de percibir el censo que les

\footnotetext{
${ }^{18}$ Mendoza, Municipios, cofradias y tierras.

19 CAmacho, "De la desamortización a la reforma agraria"; Marino, "La modernidad a juicio".

20 Colección de decretos, decreto de 20 de octubre de 1868.

21 Riguzzi, "El camino hacia la modernidad", p. 229.
} 
concedía la ley. ${ }^{22}$ Existen varios momentos en que se aceleró la privatización y que responden a nuevas reglas legales y cuestiones tanto económicas como fiscales. Un primer momento lo podemos situar en la promulgación de la Ley Lerdo y la guerra de tres años y se caracteriza por la escasa aplicación. Pero en el año 1861 tenemos datos precisos de que muchos vecinos de los pueblos y barrios del municipio de San Juan Teotihuacán solicitaron la adjudicación de sus terrenos de común repartimiento; 147 vecinos se presentaron ante el alcalde de San Juan Teotihuacán manifestando que "estaban en quieta y pacífica posesión de su sitio solar" o "de sus terrenos de cultivo", y "teniendo presente la ley de 25 de junio de 1856", solicitaron la adjudicación. Es decir, que estos terrenos ya estaban en su poder. En esta misma lista se agregaron cinco personas, quienes solicitaron se les adjudicara en propiedad nueve terrenos que eran de comunidad, cuatro más solicitaron tierras que pertenecían a "la comunidad religiosa” y cinco más denunciaron siete terrenos que estaban en conflicto entre familiares. Las solicitudes para adjudicarse tierras fueron numerosas, y hasta hubo quienes solicitaron tierras que estaban en manos de la Iglesia católica. Por ejemplo, en el pueblo de San Martín se presentó un tal Leandro Martínez manifestando "que habiendo un pedazo de terreno de la comunidad religiosa teniendo magueyes cimarrones y nopales perteneciente a este pueblo y teniendo necesidad de ella para que pueda remediar la felicidad de mi subsistencia y sólo necesitando en donde pueda caber seis cuartillos de sembradura de maíz", solicitó

22 Birrichaga, “Administración de tierras y bienes comunales”, pp. 260 y 275-276. 
que se le adjudicara en propiedad en cumplimiento de la ley de 25 de junio de 1856, quedando "obligado a reconocer sobre la tierra el capital que ella valga y a pagar el rédito que le corresponda a razón del seis por ciento anual" ${ }^{23}$ Lo mismo hicieron Canuto Alonso, Tomás Villanueva y José Alejandro, que también solicitaron un terreno conocido con el nombre de Atlaxelucan, "perteneciente a la comunidad de la iglesia”. El primero pidió seis cuartillos, el segundo seis y el tercero diez cuartillos. Así, el terreno que pertenecía a la iglesia fue dividido entre varios solicitantes.

Llama la atención que muchos campesinos tenían en su poder varias parcelas. En total se solicitaron para su adjudicación 420 terrenos. Así tenemos que en promedio cada campesino tenía cerca de tres terrenos (2.7). Pero en términos más detallados había campesinos que registraron entre cinco y seis tierras de cultivo, más aparte el sitio solar donde habitaban; cinco personas manifestaron que poseían un solo terreno, 50 tenían dos, 39 tenían tres, 39 poseían cuatro, 10 tenían cinco; dos tenían seis y una persona dijo poseer siete parcelas de cultivo. Lo que indica que desde antes de aplicarse las leyes desamortizadoras ya existía una incipiente acumulación de tierras y ciertas diferencias sociales y económicas entre los habitantes de los pueblos de San Juan Teotihuacán. Diferencias que se acrecentarían en las décadas siguientes.

Los terrenos que fueron adjudicados en este año y los siguientes continuaron denominándose "terrenos de común repartimiento", pero a diferencia del pasado, ahora tendrían que pagar un rédito sobre su valor total a la tesorería

${ }^{23}$ AHMTEO, Tierras, c. 1, Solicitudes para adjudicaciones, 1861, ff. 1-40. 
municipal. En otras palabras, la escritura de adjudicación otorgada por el ayuntamiento o la jefatura política facilitó las transferencias de parcelas y el censo redimible debería ser pagado por el comprador, lo que paulatinamente consolidaría la pequeña propiedad privada.

Cabe señalar que, para definir a la propiedad privada, seguimos las aportaciones de la filosofía política de Macpherson, quien apunta tres características básicas, en primer lugar, que "la propiedad privada es el derecho de un individuo a excluir a otro del uso o los beneficios de alguna cosa, mientras que la propiedad común es el derecho de un conjunto de individuos a no ser excluidos del uso de los beneficios de alguna cosa”. El segundo elemento es verla como una relación social, y tercero, que la propiedad privada no puede entenderse al margen del Estado. ${ }^{24}$ Este es el caso de la propiedad privada liberal que con la nueva legislación se constituyó en un derecho protegido por el Estado, que asumió como una de sus funciones principales la defensa de las propiedades particulares, en nombre del sagrado derecho de propiedad, ${ }^{25}$ pero más allá de la ley, tanto los pueblos como los adjudicatarios indígenas y mestizos incrustaron su propia visión sobre la propiedad de la tierra de acuerdo a sus conveniencias.

Como hemos visto, cada ciudadano solicitó entre dos y cinco parcelas que previamente tenían en "quieta y pacífica posesión”. Y no se resistieron a cambiar su régimen de propiedad y su antigua organización comunitaria; como se ha dicho, por el contrario, muchos campesinos que poseían

\footnotetext{
${ }^{24}$ Macpherson, Property, p. 4.

${ }^{25}$ Congost, Tierras, leyes, historia, p. 154.
} 
sus parcelas de cultivo acudieron muy pronto ante la autoridad local y la jefatura política para obtener un título legal de propiedad sobre las tierras que antes usufructuaban. Esto sin duda porque les daba mayor seguridad no sólo para protegerlas ante la ambición de familiares y vecinos, sino también para hacerlas a un lado de la vigilancia de las autoridades locales (recuérdese que anteriormente, en caso de no ser cultivada una parcela, la autoridad local tenía el derecho de otorgarla a otra familia).

Dicho de otro modo, las haciendas no usurparon las tierras de los pueblos a partir de la desamortización, como se ha dicho; no tuvieron necesidad de hacerlo pues ahora había otros mecanismos legales para adquirirlas sin tener que enfrentar largos litigios como en el pasado, sin que esto signifique que no proliferaran pleitos entre haciendas y pueblos por los recursos de la tierra, montes y aguas. Lo que quiero resaltar es que muchos campesinos pobres vendieron sus parcelas, ya sea de manera voluntaria o a veces forzada, y los precios variaron según su tamaño y calidad.

Entre 1869 y 1875 hubo otro momento importante en la adjudicación de los terrenos comunales; la mayoría de los campesinos que todavía no privatizaban sus terrenos acudieron a la tesorería municipal para registrar sus terrenos y en marzo de 1875 se hizo un informe de los terrenos adjudicados en el municipio de San Juan Teotihuacán. En la lista se aprecia el nombre del pueblo o barrio, nombre del adjudicatario, valor y réditos de terrenos de labor y sitios de casa solar. ${ }^{26}$ Por ejemplo, en 1869 se anotaron 103 adjudicatarios que

${ }^{26}$ Se anotaron vecinos de la cabecera de San Juan Teotihuacán y sus pueblos y barrios siguientes: Maquixco, San Martín, Purificación, San 
registraron 24 sitios solares y 240 terrenos de labor, y en el transcurso de 1870 acudieron 271 personas inscribiendo en el registro de la tesorería 527 terrenos de labor. Las adjudicaciones continuaron con la misma intensidad en los siguientes cuatro años. ${ }^{27}$

Durante el régimen porfiriano, la Secretaría de Gobierno envió una circular el 12 de mayo de 1890 a los gobiernos de los estados para que "los terrenos conocidos con el nombre de terrenos de común repartimiento procedan a convertirse en propiedad privada"; varios gobernadores a su vez ordenaron a los jefes políticos extender los certificados de adjudicación. En el Estado de México se continuó cobrando el censo en favor del ayuntamiento, impuesto que según Molina venía percibiendo desde el decreto de 9 de mayo de 1833, por lo tanto se mantuvo la condición contractual del municipio como "censualista" y la del adjudicatario como "censatario". ${ }^{28}$ En otras palabras, en adelante, todos los terrenos o predios de origen comunal o de repartimiento quedarían sometidos al pago de la contribución predial que causa la propiedad en el estado, como se percibe en el decreto 49, emitido por el gobernador Vicente Villada en 1897:

Art. 2. Los poseedores de terrenos o predios que fueron de origen comunal, de común repartimiento o del dominio de los ayuntamientos, que hasta la fecha no consten en los registros municipales del distrito a que correspondan, dentro del

Lorenzo, Santiago Tolman, Puxtla, San Sebastián, Belem, San Francisco, Coatlán, Zacualuca, Totolcingo y Tepexpan. AHMTEO, Tierras, c. 3 y 4, Adjudicaciones de tierras, 1869-1875, ff. 3-85.

27 AHMTEO, Tierras, c. 3 y 4, Adjudicaciones de tierras 1869-1875.

${ }^{28}$ Molina, Breve estudio para la determinación jurídica, p. 38. 
improrrogable término de tres meses, expresando su ubicación, extensión en hectáreas, áreas y centiáreas cuadradas y su valor, para que sean inscritos en los registros respectivos [...].

Art. 6. Para verificar la recaudación de la contribución predial que se impone por el presente decreto, los administradores de las rentas municipales formarán un registro general de las propiedades afectadas a los impuestos del ocho al millar y tres por ciento anual, así como de las que por haber sido del dominio de los ayuntamientos, causen al censo del seis por ciento anual. ${ }^{29}$

Es por ello que durante estos años la mayoría de los "propietarios” de los terrenos de común repartimiento acudieron a la tesorería municipal para certificar sus terrenos, anotando el nombre del terreno, ubicación, medidas, colindantes y valor respectivo. Los terrenos subieron de valor y por tanto tenían que regularizarse ante el gobierno local. Este tipo de relaciones contractuales le convenían al municipio porque seguía recibiendo importantes recursos fiscales. Para la segunda década del siglo xx esta legislación mantenía su vigencia conforme al dominio del derecho público en el que se fijó el censo sobre los bienes municipales, estableciéndose que "en tanto que no se redima el censo pactado en la adjudicación el Municipio se mantiene en propiedad del inmueble obligado, rural y urbano". 30

Otro momento importante en la transferencia de tierras, montes y aguas se dio en la última década del siglo XIX. En diciembre de 1897, mediante la circular número 62, se

${ }^{29}$ Colección de decretos expedidos por el décimo séptimo Congreso Constitucional, 1899, t. XXV, pp. 94-96.

30 Molina, Breve estudio para la determinación jurídica, pp. 38 y 47. 
dispuso que los presidentes municipales del distrito procedieran a la formación de los padrones de los terrenos sujetos al pago de los impuestos municipales. Por ello, existe un expediente en el archivo relativo a la "Remisión a la jefatura política el padrón de Terrenos de propios de este ayuntamiento y de común repartimiento". A los campesinos no les quedó más alternativa que acudir otra vez ante el tesorero municipal y manifestar sus terrenos de cultivo que poseían como de común repartimiento, con sus medidas, colindantes y respectivo valor. Sin embargo, dos años después, el jefe político de Texcoco se dirigió al presidente de Teotihuacán, con el objeto de adjudicar los terrenos que corresponden a los bienes propios del ayuntamiento o los de común repartimiento, señalando que muchos vecinos:

No han hecho manifestación de aquellos que poseen sin título legal o que habiéndolo manifestado no han pedido su adjudicación para obtener su escritura. Y para que no se perjudique la municipalidad con la falta de pagos de las contribuciones que causan dichos terrenos, y para que la propiedad esté debidamente asegurada en beneficio de las personas que poseen los referidos terrenos. Que se les prevenga a los vecinos que si en un plazo de 30 días no acudan a manifestarlos, la jefatura las adjudicará conforme lo establece la ley a las personas que las denuncien. ${ }^{31}$

Quizá por eso, una vez más, desde los últimos años del siglo XIX hasta 1905, muchos vecinos de los barrios y pueblos del municipio de Teotihuacán acudieron a la tesorería

31 AHMTEO, Tierras, c. 6, Sobre terrenos de común repartimiento y propios, 1889. 
municipal a manifestar sus terrenos de común repartimiento mencionando sus medidas, colindantes y valor de su terreno. Todo con tal de obtener su escritura, pagar su contribución y obtener seguridad legal sobre sus propiedades. Un padrón de 1900 registró a 232 causantes sujetos a pago de la contribución predial de 11 al millar anual sobre terrenos de común repartimiento ubicados en el pueblo de Atlatongo y barrio de San Agustín. Por ejemplo, Bernardo Alcántara tenía de "capital según el padrón" 508.39 y tuvo que pagar $11 \%$ al millar, es decir, cubrió $5.60 .^{32}$ En cambio, para las arcas municipales, el cobro del impuesto predial de las tierras de común repartimiento representaba un porcentaje considerable de sus ingresos a principios del siglo xx, lo que contradice lo que se ha dicho para los municipios durante el porfiriato; según algunos investigadores, éstos perdieron poder y autonomía ante la jefatura política y solamente fueron entidades administrativas. ${ }^{33}$ Sin embargo, algunos municipios continuaron manejando los asuntos locales y cobrando diversos impuestos para sostener la administración pública. En el Estado de México fueron importantes los ingresos que generaban los terrenos de común repartimiento. Veamos sólo un ejemplo de los presupuestos y cuentas municipales.

En abril de 1900 el presidente municipal de Teotihuacán recibió una circular por parte del "Superior Gobierno" para la formación del presupuesto de egresos del año siguiente. Se le ordenaba que tuviera presentes los recursos probables

\footnotetext{
32 AHMTEO, Tierras, c. 7, Padrón de adjudicaciones, 1900.

33 Merino, Gobierno local, poder nacional, pp. 14 y 221; Meyer, "El municipio mexicano", p. 237.
} 
con que contaba para el sostenimiento de la administración y remitiera el presupuesto, donde debía incluir: 1) el Producto de réditos de capitales impuestos sobre cualquier predio, con excepción de los que fueran propios del ayuntamiento, 2) sobre predios que fueran propios, 3) licencia de corte de madera, 4) corte de leña, 5) elaboración de carbón y trementina, 6) raíz de zacatón, 7) arrendamiento para pastos de ganado en terrenos propios del ayuntamiento, 8) mercedes de agua propiedad de municipalidades para regadío, 9) uso de agua para fuerza motriz, 10) extracción de sal, 11) licencias para hacer uso de lagunas para pesca, 12) caza de patos, 13) corte de tule, 14) extracción de tequesquite, 15) cantera y tezontle, 16) nieve, 17) cal y yeso, 18) arena de ríos, 19) arrendamiento de locales propios del ayuntamiento. ${ }^{34}$

Como se puede observar en este documento oficial, los municipios seguían obteniendo impuestos por arrendamiento de los propios del ayuntamiento, lo que refleja que muchos gobiernos locales todavía conservaban la representación de estos bienes comunales mientras no se cubriera el pago total del terreno y obtuvieran su escritura privada definitiva. El presidente envió el presupuesto general de ingresos para el año siguiente (1901).

${ }^{34}$ AHMTEO, Tesorería, Circular núm. 78 de 26 de marzo de 1900, enviada por el jefe político de Texcoco al presidente de Teotihuacán. $\mathrm{Al}$ parecer los propios del ayuntamiento ya no eran tierras de cultivo sino locales que se arrendaban en una esquina del mercado municipal; este dinero ingresaba a la tesorería y se utilizaba para financiar la administración municipal. 


\section{Cuadro 1}

PRESUPUESTO DE INGRESOS AÑO 1901

\begin{tabular}{|l|r|}
\hline & Pesos \\
\hline Sobrante año anterior (1900) & 96.00 \\
\hline $\begin{array}{l}\text { Producto capital impuesto sobre predios que fueron } \\
\text { propios del ayuntamiento }\end{array}$ & 9.00 \\
\hline 6\% a terrenos de propios del ayuntamiento & 163.20 \\
\hline 11 al millar por contribución predial & 778.70 \\
\hline Agentes de seguro & 1.00 \\
\hline Banqueros y prestamistas & 72.00 \\
\hline Casas de empeño & 46.67 \\
\hline Carros & 253.55 \\
\hline Corral de consejo & 5.00 \\
\hline Comerciantes ambulantes & 10.00 \\
\hline Canales, goteras y tejados & 2.00 \\
\hline Diversiones públicas & 5.00 \\
\hline Fiel contraste & 211.34 \\
\hline Giros mercantiles & 37.40 \\
\hline Hoteles y mesones & 24.50 \\
\hline Juegos permitidos & 5.00 \\
\hline Licencia pulquerías & 181.25 \\
\hline Matanzas de cerdos & 321.31 \\
\hline Ordeña de vacas & 1.00 \\
\hline Profesiones, ejercicios lucrativos & 82.50 \\
\hline Mercados & 336.73 \\
\hline Registro civil & 5.00 \\
\hline Pailas tenerías & 5.00 \\
\hline Fierros quemadores & 3.00 \\
\hline Recargos a causantes morosos & 23.00 \\
\hline Total & 739.18 \\
\hline Fes & 1900 \\
\hline
\end{tabular}

Fuente: AHMTEO, Tesorería, Presupuesto General de ingresos 19001901. 
El cuadro nos muestra cómo la contribución predial era la más importante y alcanzaba más de 30\% del total de los ingresos. Aunque el municipio de Teotihuacán carecía de recursos naturales como los pueblos del valle de Toluca, para subsanar sus arcas tuvo que incluir otros impuestos como el de profesiones y matanza de cerdos, entre otros que no venían en la circular mencionada.

Todavía en 1925 los ingresos por el impuesto de terrenos de común repartimiento eran similares; el presidente municipal de Teotihuacán informó a la Secretaría General de Toluca que el monto recaudado en dicho año fue de 734.34 pesos, sin incluir los denominados "propios del ayuntamiento". ${ }^{35}$ Sin embargo, en los ingresos de 1931 de un total de 8503.62 , por el pago del impuesto predial ingresaron 888.20. Para estos años, otros rubros estaban superando los ingresos de terrenos, por ejemplo, por mercados ingresaron 2016.75 y 1328.75 por rastros. ${ }^{36}$

\section{COMPRAVENTA DE TIERRAS}

Desde la década de 1870 la compraventa de tierras aumentó de manera considerable y cada transacción se registró en el archivo municipal. El interés por la propiedad privada se intensificó conforme pasaron los años y el valle de Teotihuacán se fue vinculando con mayor ímpetu al mercado de la Ciudad de México. En este contexto más comercial, los hacendados, rancheros, comerciantes locales y foráneos aumentaron sus inversiones y compraron las tierras más

35 AHMTEO, Tesorería, Presupuesto de ingresos y egresos 1926.
36 AHMTEO, Tesorería, Presupuesto de ingresos y egresos 1932. 
fértiles para cultivar nuevos productos como alfalfa, hortalizas y leche. A fines del siglo xix, con el desarrollo económico porfirista y la llegada del ferrocarril, las tierras subieron de valor y fueron cada vez más codiciadas por comerciantes locales e inversionistas foráneos, a tal grado que muchos campesinos vendieron sus tierras tanto a unos como a otros. El resultado fue el aumento de la superficie de las haciendas y el surgimiento de varios ranchos.

Los pudientes locales acumularon pequeñas parcelas de cultivo que paulatinamente fueron comprando con los campesinos más pobres. Por ejemplo, en agosto de 1904, el testamento de Ascencio Valencia menciona 19 terrenos "de común repartimiento" que dejó a su señora Loreto Victoria en el pueblo de Atlatongo.

\section{Cuadro 2}

TESTAMENTO DE ASCENSIÓN VALENCIA, 1904

\begin{tabular}{|c|l|r|}
\hline Terreno & Pueblo de Atlatongo & Valor \\
\hline Común repartimiento & Capultitla & 117.60 \\
\hline “ & Sentlapal & 13.28 \\
\hline “ & Sentlapal & 30.80 \\
\hline “ & Sacamilpa & 73.98 \\
\hline “ & Huitzila & 24.98 \\
\hline “ & Huitzila & 25.90 \\
\hline “ & Hueyotlica & 16.48 \\
\hline “ & Tlacomulco & 136.76 \\
\hline “ & Tlacomulco & 55.60 \\
\hline & Tlacomulco & 68.47 \\
\hline & Tlacomulco & 85.65 \\
\hline
\end{tabular}




\begin{tabular}{|c|l|r|}
\hline Terreno & Pueblo de Atlatongo & Valor \\
\hline “ & Olivaco & 155.94 \\
\hline “ & Olivaco & 69.60 \\
\hline “ & Potratenco & 250.92 \\
\hline “ & Potratenco & 5852 \\
\hline “ & Xocicuayo & 414.48 \\
\hline “ & Tenexcahuca & 5.28 \\
\hline “ & Ocuila & 16.60 \\
\hline Total & Yetlahuaca & 32.76 \\
\hline
\end{tabular}

Fuente: AHMTEO, Tierras, c. 11, Testamento de Ascensio Valencia, 1904.

Los hacendados también compraron tierras a los campesinos; por ejemplo, en la década de 1920 varios hacendados mostraron las escrituras de los terrenos de común repartimiento que habían comprado a los campesinos locales. Todavía, el 29 de marzo de 1921 Epifanio Torres y José Teófilo Torres, vecinos del barrio de San Lorenzo, vendieron un terreno de "común repartimiento" a Ángel Arratia, dueño de la hacienda Santa Catarina, por 60 pesos. ${ }^{37}$

De la misma forma, la tierra de la cofradía de 8 ha que era propiedad del H. Ayuntamiento aparece después como propiedad de la hacienda Cadena y Anexas. En 1922 la hacienda Cadena tenía una extensión de 1060 ha y estaba conformada por hacienda Cadena 619.46 ha; rancho El Inglés, 414.67; tierra de la cofradía, 8.21 ha; tierra Ahuehuetes 7.07 ha y tierras Texopa; $11.00 .{ }^{38}$

${ }^{37}$ AHMTEO, Tierras, c. 13, Compraventas de tierras, 1921.

38 AHMTEO, Tierras, c. 13, Compraventas de tierras, 1922. 
Hubo compañías que también adquirieron tierras en esta zona; en 1904 The Mexican Light and Power Company Limited, por medio de su representante Emilio Trigueros, compró a varios campesinos 30 terrenos de común repartimiento. Los terrenos estaban ubicados en Teotihuacán; la extensión y el precio que se pagó por cada terreno era muy variable y dependía tanto de su calidad como de su ubicación. Por ejemplo, un terreno de $1061 \mathrm{~m}^{2}$ tuvo un valor de 48 pesos, mientras otro terreno de $1264 \mathrm{~m}^{2}$ tuvo un costo de 423.3. En cambio, hubo terrenos de $10018 \mathrm{~m}^{2}$ que sólo alcanzaron un valor de 400 pesos. La suma total por la compra de los 30 terrenos importó 4312 pesos. ${ }^{39}$

En el mismo año 1904, el señor Ramón Gantun vendió a Teodoro van Engelbrecht dos terrenos de común repartimiento ubicados en Teotihuacan por el precio de 500 pesos; la escritura se registró ante notario público. En la misma fecha Juan Carrasco vendió a Catalina Ortiz Janso de Casas un terreno denominado Cofradía ubicado tras la iglesia parroquial de Teotihuacán por 3015 pesos. $^{40}$

En términos generales la desamortización permitió que una parte de los campesinos conservara en su poder su pequeña propiedad que poseía antes de 1856, pero con el tiempo muchos campesinos pobres empezaron a vender sus propiedades, a tal grado que para 1920, la mayor parte del territorio municipal estaba en manos de las haciendas y los ranchos. El pueblo de Teotihuacán y sus barrios sólo conservaban 1216 ha repartidas de la siguiente manera: Cabecera (66 ha); barrio La Purificación (221.30); San Lorenzo

39 AHMTEO, Tierras, c. 11, Compraventas de tierras, 1904.
40 AHMTEO, Tierras, c. 11, Compraventas de tierras, 1904. 
(99.10); Puxtla (22); Maquixco (123.80); San Juan Evangelista (69.50); San Sebastián (605). ${ }^{41}$

En cambio, las tierras particulares que rodeaban San Juan Teotihuacán y sus barrios eran las siguientes:

\section{Cuadro 3}

TIERRAS DE LAS PROPIEDADES PARTICULARES QUE LIMITABAN CON SAN JUAN TEOTIHUACÁN

\begin{tabular}{|l|l|c|}
\hline Hacienda & Cadena y anexos & 1060.00 ha \\
\hline Hacienda & Santa Catarina (fracción 2) & 497.50 \\
\hline Hacienda & Tlajinga & 1072.90 \\
\hline Rancho & Oxtoyahualco & 1039.00 \\
\hline Rancho & Tierras de Meneses & 68.50 \\
\hline Rancho & Santa Ana & 34.50 \\
\hline Rancho & Huixcoloco & 167.50 \\
\hline Rancho & San Mateo & 152.70 \\
\hline & Zona de las Pirámides & 222.50 \\
\hline Total & & 4312 \\
\hline
\end{tabular}

FuENTE: AGA, Solicitud de dotación de ejidos municipio de Teotihuacán, exp. 23/2275, leg. 1 , f. 395.

Para las primeras décadas del siglo xx, la mayor parte de las tierras de cultivo y los sistemas de riego del valle de Teotihuacán estaban en manos de hacendados, rancheros y pequeños propietarios, quienes al amparo de las leyes habían confirmado sus derechos de aguas sobre los manantiales y barrancas y también estaban pagando sus impuestos

${ }^{41}$ AGA, Dotación de ejidos, Solicitud de dotación de ejidos del municipio de Teotihuacán, exp. 23/2275, leg. 1, f. 396, México. 
prediales; ${ }^{42}$ en cambio, los pueblos habían perdido la mayor parte de sus propiedades comunales. Según Manuel Gamio, antes de la reforma agraria $90 \%$ de la superficie del municipio de Teotihuacán estaba en manos de cinco terratenientes y el $10 \%$ restante pertenecía a poco más de 500 pequeños propietarios. ${ }^{43}$ De acuerdo con Margarita Nolasco, quien hizo un estudio detallado de la tenencia de la tierra en Teotihuacán, ${ }^{44}$ y según los padrones de pequeños propietarios que hemos consultado, se deduce que la pequeña propiedad antes de la reforma agraria tenía poco más de $25 \%$ del territorio municipal y que este tipo de propiedad se acrecentó a partir de dicha reforma, pues muchas haciendas no sólo se dotaron a ejidos sino que otra parte importante quedó en las mismas familias de exhacendados y sus herederos.

La revolución mexicana de 1910 y la reforma agraria generarían cambios sobre el régimen de propiedad y darían lugar a otro tipo de relaciones de producción; al mismo tiempo, crearían nuevas fuentes de conflictos entre los distintos actores sociales.

\section{LA REFORMA AGRARIA Y LA DOTACIÓN DE EJIDOS}

La ley agraria de 6 de enero de 1915 declaró nulas “todas las enajenaciones de tierras, aguas y montes pertenecientes a los pueblos, rancherías, congregaciones y comunidades hechas por los jefes políticos, en contravención a lo

${ }^{42}$ Mendoza, "Los municipios de San Gabriel Chilac y San Juan Teotihuacán”, pp. 375-380.

43 Gamio, La población del valle de Teotihuacán, vol. 3, p. 769.

${ }^{44}$ Nolasco, "La tenencia de la tierra", p. 65. 
dispuesto en la ley de 25 de junio de $1856 " .{ }^{45}$ Esto abrió la posibilidad para restituir las tierras que los pueblos habían perdido mediante el despojo, es decir, por condiciones o mecanismos distintos a la Ley Lerdo, pero no en los casos en que se había privatizado conforme a lo dispuesto por dicha ley. Estos preceptos se plasmaron en el artículo 27 constitucional, donde además se estableció que "la propiedad de las tierras y aguas comprendidas dentro de los límites del territorio nacional, corresponden originariamente a la nación" y por tanto, "la nación tendrá en todo tiempo el derecho de imponer a la propiedad privada las modalidades que dicte el interés público". ${ }^{46}$ Con tal política, se trató de proteger a los campesinos para no volver a repetir los despojos perpetrados por el proceso de desamortización, el deslinde y titulación de los baldíos que se llevó a cabo durante la segunda mitad del siglo xix y primera década del $\mathrm{xx}^{47}$ Pero, al mismo tiempo, la propia Constitución de 1917 propugnó por el respeto de la pequeña propiedad privada en estos términos: "la nación [...] ha tenido y tiene el derecho de trasmitir el dominio de ellas a los particulares constituyendo la propiedad privada". ${ }^{48}$

${ }^{45}$ Fabila, Cinco siglos de legislación, pp. 247-250.

${ }^{46}$ Fabila, Cinco siglos de legislación, p. 281.

47 Kourí, "Los pueblos y sus tierras", pp. 235 y 288-305.

48 Según Molina Enríquez "la nación era sucesora jurídica del rey" y tenía "el derecho de propiedad sobre todas las tierras y aguas" y podía conceder a los particulares sólo el dominio. Pero en el nuevo régimen posrevolucionario no podía decirse lo mismo. La Constitución reguló las concesiones de tierras para proteger el territorio nacional, así los extranjeros sólo podían obtener concesiones mediante la Secretaría de Relaciones Exteriores y no podían invocar la protección de sus gobiernos sobre dichos bienes. Un análisis detallado del artículo 27 constitucional y la 
Con la nueva legislación agraria muchos pueblos del Estado de México empezaron a solicitar la restitución de sus tierras comunales, pero como los trámites eran complicados porque se les solicitaba que mostraran sus títulos respectivos y comprobaran el despojo de sus propiedades, optaron por la dotación de ejidos. ${ }^{49}$ Fue así como en el municipio de Teotihuacán varios núcleos agrarios fueron favorecidos en las décadas de 1920 y 1930.

La reforma agraria transformó el sistema de propiedad en México, no sólo desarticuló al gran latifundio sino también fomentó la amortización de gran parte de las tierras por medio de la dotación de ejidos y la restitución de tierras comunales. En el valle de Teotihuacán varios pueblos y núcleos de población solicitaron la dotación de ejidos, y pese a la notable oposición de los terratenientes finalmente se fragmentaron las haciendas. ${ }^{50}$ Por ejemplo, en agosto de 1920, el señor Braulio Hernández, como representante del pueblo de San Juan Teotihuacán y sus barrios, solicitó la dotación de ejidos. En su petición argumentaba la pobreza de los campesinos pues las haciendas Santa Catarina y La Cadena "han invadido hasta los corrales del pueblo $y$ la gente se encuentra en la mayor miseria y vive en ruinas pues apenas tiene para comer"; sin embargo reconocía algo importante, "Los terrenos que pertenecían al pueblo como ejidos y que por virtud de la ley de desamortización se dieron a particulares, éstos las han vendido parte a las haciendas

propiedad privada puede verse en Escalante, "El lenguaje del artículo 27 constitucional", pp. 238-242.

${ }^{49}$ Lo mismo sucedió en otras regiones de Puebla, Oaxaca y Veracruz. Velasco, García y Domínguez, La ley del 6 de enero de 1915.

${ }^{50}$ Mendoza, "Oposición al reparto agrario". 
y actualmente pretenden vender a las mismas y se niegan a hacerlo con el pueblo". ${ }^{51}$ Lo que confirma que las tierras fueron compradas por los hacendados a los campesinos locales. En su defensa, los dueños de las haciendas manifestaron que no procedía la dotación, en primer lugar, porque la población no llegaba a 1000 habitantes, y en segundo, porque los solicitantes eran pequeños propietarios. Además, señalaron que muchos de los solicitantes eran comerciantes y tenían oficios diversos que demostraban que no eran campesinos; en el censo que confirmó la autoridad municipal estaban anotados carniceros, sastres, albañiles, carpinteros, boticarios, telegrafistas, ganaderos y propietarios de terrenos y casas. Asimismo apuntaron que otros anotados eran difuntos o no eran vecinos del pueblo. ${ }^{52}$ Por ejemplo, había hombres con fortunas considerables: Adrian de la $\mathrm{O}$ era propietario de casas y terrenos de riego y temporal, y por si fuera poco era comerciante, tenía 30 cabezas de ganado vacuno, 30 mulas y 40 cabezas de ganado lanar y cabrío. También se señaló que Braulio Hernández, el representante agrario de Teotihuacán, era “industrial, propietario de un molino de nixtamal y otras propiedades". Incluso estos datos fueron confirmados por un interrogatorio de testigos, no sabemos si comprados, pero sea como fuere es evidente que el censo refleja la indudable estratificación social. ${ }^{53}$

${ }^{51}$ AGA, Dotación de ejidos, San Juan Teotihuacán, exp. 23/2275, leg. 1, ff. 1-2.

52 AGA, Dotación de ejidos, San Juan Teotihuacán, exp. 23/2275, leg. 1, ff. 161-162.

${ }^{53}$ AGA, Dotación de ejidos, San Juan Teotihuacán, exp. 23/2275, leg. 1, f. 166. 
Los hacendados trataron de probar que sus tierras no eran grandes latifundios, sino que se trataba de una pequeña propiedad que contaba con industria. Por ejemplo, la hacienda Santa Catarina, que previamente había sido dividida en dos fracciones, una de las cuales pertenecía a Ángel Arratia, contaba con 497 ha donde se sembraba maíz, cebada, alfalfa y maguey. Tenía 80 ha de riego donde se cultivaba alfalfa y 150 de temporal, el resto estaba plantado de magueyes. El dueño arguyó que se trataba de una industria pues contaba con 320 vacas finas de ordeña, establos acondicionados, un tinacal para la elaboración de pulque y como industria secundaria tenía ganado porcino y lanar fino. ${ }^{54}$

Pese a la oposición de los hacendados, finalmente el reparto de sus tierras fue inevitable y para fines de la década de 1920 ya se habían formado varios núcleos ejidales. A mediados del siglo xx existían 7 ejidos y ampliaciones con 1262 ejidatarios en el municipio de San Juan Teotihuacán. ${ }^{55}$

\section{Cuadro 4}

DOTACIÓN DE EJIDOS Y AGUAS EN EL VALLE DE

SAN JUAN TEOTIHUACÁN

\begin{tabular}{|l|c|c|c|}
\hline Ejido & $\begin{array}{c}\text { Dotación } \\
\text { total de } \\
\text { tierras }\end{array}$ & $\begin{array}{c}\text { Dotación de } \\
\text { tierras con } \\
\text { riego de los } \\
\text { manantiales }\end{array}$ & $\begin{array}{c}\text { Fecha resolución } \\
\text { presidencial }\end{array}$ \\
\hline San Juan Teotihuacán & $893.00 \mathrm{ha}$ & $57.96 \mathrm{ha}$ & $\begin{array}{c}23 \text { de abril } \\
\text { de } 1925\end{array}$ \\
\hline Atlatongo & 273.1667 & $153.07-53$ & $\begin{array}{c}3 \text { de diciembre } \\
\text { de } 1925\end{array}$ \\
\hline
\end{tabular}

${ }^{54}$ AGA, Dotación de ejidos, San Juan Teotihuacán, exp. 23/2275, leg. 1, f. 381 .

${ }^{55}$ Nolasco, "La tenencia de la tierra", p. 67. 


\begin{tabular}{|c|c|c|c|}
\hline Ejido & $\begin{array}{l}\text { Dotación } \\
\text { totalde } \\
\text { tierras }\end{array}$ & $\begin{array}{l}\text { Dotación de } \\
\text { tierras con } \\
\text { riego de los } \\
\text { manantiales }\end{array}$ & $\begin{array}{c}\text { Fecha resolución } \\
\text { presidencial }\end{array}$ \\
\hline San Bartolo Acolman y barrios & 302.50 & 136.5 & $\begin{array}{c}4 \text { de febrero de } \\
1926\end{array}$ \\
\hline $\begin{array}{l}\text { Calvario Acolman y sus } \\
\text { barrios }\end{array}$ & 650.00 & 337.00 & $\begin{array}{c}24 \text { de julio de } \\
1924\end{array}$ \\
\hline $\begin{array}{l}\text { Ampliación de Acolman, } \\
\text { corresponde al Barrio de San } \\
\text { Pedro Tepetitlán }\end{array}$ & 113.60 & 32.00 & $\begin{array}{c}15 \text { de agosto de } \\
1929\end{array}$ \\
\hline Barrio de San Pedro Tepetitlán & 118.29 & 26.96 & $\begin{array}{c}2 \text { de mayo de } \\
1929\end{array}$ \\
\hline Xometla & 400.00 & 205.72 & $\begin{array}{c}8 \text { de mayo de } \\
1924 \\
\end{array}$ \\
\hline Tequisistlán & 383.00 & 140.00 & $\begin{array}{l}2 \text { de septiembre } \\
\text { de } 1921\end{array}$ \\
\hline Nexquipayac & 490.00 & 111.28 & $\begin{array}{c}15 \mathrm{de} \\
\text { noviembre de } \\
1925\end{array}$ \\
\hline Ampliación Nexquipayac & & $64.99-50$ & $\begin{array}{c}29 \text { de agosto de } \\
1929\end{array}$ \\
\hline Ixtapan & 498.00 & 265.94 & $\begin{array}{c}5 \text { de mayo de } \\
1921\end{array}$ \\
\hline Santa Catarina & 694.00 & 96.70 & $\begin{array}{c}11 \text { de agosto de } \\
1927\end{array}$ \\
\hline Cuanalán & 370.00 & 353.00 & $\begin{array}{c}8 \text { de mayo de } \\
1924\end{array}$ \\
\hline Tepexpan & 488.00 & 128.94 & $\begin{array}{c}2 \text { de septiembre } \\
\text { de } 1921\end{array}$ \\
\hline San Mateo Chipiltepec & 289.1231 & $47.24-65$ & $\begin{array}{c}3 \text { de marzo de } \\
1923\end{array}$ \\
\hline
\end{tabular}

Fuente: AGA, Dotación de ejidos, municipio de San Juan Teotihuacán, exp. 23/2275. 
Los ejidos también exigieron la dotación de aguas para irrigar sus terrenos, de modo que el sistema de riego de las aguas de los manantiales de San Juan Teotihuacán que antes controlaban los hacendados pasó a manos de ejidatarios y pequeños propietarios. En 1927 se formó una Junta de aguas que organizaría la distribución del agua y que estaba integrada por 13 representantes ejidales, nueve pequeños propietarios y seis hacendados; sin embargo, ${ }^{56}$ lo mismo que en otras regiones, se desarticuló el sistema de riego y la producción de las haciendas, ${ }^{57}$ y ante la proliferación de regantes surgieron numerosos conflictos por el control y acceso del vital líquido entre los distintos usuarios. ${ }^{58}$

$\mathrm{Al}$ mismo tiempo que las tierras de las haciendas se transformaban en ejidos, las pequeñas propiedades, o mejor dicho las aún llamadas "tierras de común repartimiento", que tenían extensiones variables que iban desde una hasta 70 ha, continuaron en poder de sus dueños, quienes siguieron pagando sus contribuciones fiscales. Dicho de otro modo, en el valle de Teotihuacán, pese al reparto agrario, la pequeña propiedad privada no fue afectada, aunque hubo excepciones. Por ejemplo, Carlos Beristain, al ver que su propiedad estaba en peligro por la solicitud de dotación, señaló que había comprado el rancho Santa Ana de 33 ha en 8000 pesos y presentó su escritura pública, donde se apuntaba: "se compone de una casa y 14 terrenos de común

${ }^{56}$ Mendoza, "Los municipios de San Gabriel Chilac y San Juan Teotihuacán”, pp. 377-378.

57 Valladares, Cuando el agua se esfumo, pp. 73-80; Sánchez Rodríguez, "El mejor de los títulos".

${ }^{58}$ Mendoza, "Los municipios de San Gabriel Chilac y San Juan Teotihuacán”, pp. 377-380. 
repartimiento, con sus medidas y colindancias”. Esto refleja que el rancho se había constituido por compras de terrenos a campesinos locales. Beristain manifestó que algunos vecinos del barrio de San Sebastián pretendían repartirse las tierras de su rancho, pero eso "lesionará el espíritu de la Constitución de Querétaro que tiende a la formación de la pequeña propiedad a costa de los grandes latifundios”. Por lo que propuso hacer la dotación tomando tierras de las grandes haciendas que existían alrededor y no de su pequeña propiedad. ${ }^{59}$ Los campesinos que buscaban dotación de ejidos entraron en conflicto no sólo con las haciendas sino también con pequeños propietarios y rancheros. Entre 1934 y 1935 varios pueblos invadieron tierras de haciendas y de ranchos; otro caso fue el de los vecinos de Tlachachualpa, perteneciente al municipio de Temascalapa, quienes ocuparon las tierras del rancho de Tenextlacotla que ya había sido dotado por resolución presidencial a los campesinos de Zacualuca. Del mismo modo, los encargados del rancho Las Cañadas y el rancho Tenopala elevaron su queja ante el presidente de Teotihuacán para denunciar que "vecinos agraristas" de varios pueblos habían invadido las tierras de los ranchos citados, y que éstos eran de pequeña propiedad. ${ }^{60}$ En suma, al lado del ejido prevaleció la propiedad privada, y los pequeños propietarios también tuvieron

59 AGA, Dotación de ejidos, municipio de San Juan Teotihuacán, exp. 23/2275, leg. 1, ff. 78-94.

60 AHMTEO, Tierras, Por invasión de tierras, San Juan Teotihuacán, fondo Tierras, 1934-1935. Asimismo, en el transcurso de 1946, 42 vecinos de San Juan Evangelista solicitaron la expropiación de un terreno que era propiedad de María de los Ángeles Meneses. Denuncia de doña María Meneses, 1946. 
un peso significativo en el desarrollo agropecuario del país. Las siguientes líneas ilustran la importancia de los pequeños propietarios en un mundo de ejidatarios.

TIERRAS DE COMÚN REPARTIMIENTO O PEQUEÑA PROPIEDAD

En el valle de Teotihuacán prevalecieron varias formas de propiedad: el ejido individual y comunal y la pequeña propiedad privada; al mismo tiempo siguieron subsistiendo diversas formas de aparcería y mediería en las relaciones productivas de trabajo. ${ }^{61}$

La pequeña propiedad tenía su origen en el proceso de desamortización de los terrenos de común repartimiento, el fundo legal y la venta de los ejidos de los pueblos durante la segunda mitad del siglo xix. Como hemos visto, el término tierras de común repartimiento se conservó en la nomenclatura fiscal del Estado de México, y en el caso de San Juan Teotihuacán, los propietarios tuvieron que pagar un censo o impuesto predial a la tesorería municipal. Con el paso del tiempo, la posesión individual y privada otorgó derechos plenos y, por ende, el propietario podía adquirirla o transferirla por varias vías; compra, venta, donación y herencia. Los precios variaron según el tiempo y las circunstancias. ${ }^{62}$

61 Nolasco, "La tenencia de la tierra”, pp. 67-75.

62 AHMTEO, Tierras, La hectárea de terreno de $1^{\mathrm{a}}$ clase, o sea, la de riego, tiene un valor de 30 pesos; la de segunda, o sea, la de jugo malo 20 pesos, y la de tercera o sea tierras de temporal, de agostadero y delgadas tienen un valor de 4 pesos, todos estos valores corresponden a terrenos de esta municipalidad. 1919. Caja que contiene los años de 1919 a 1931. AHMTEO. En 1939 los precios se elevaron; los terrenos "tierras 
Entre 1925 y 1940 casi todos los pequeños propietarios solicitaron al Juzgado Auxiliar de Teotihuacán un "documento certificado" para demostrar que eran dueños de sus terrenos de común repartimiento, lo que refleja que, al momento de efectuarse la formación de ejidos, trataron de proteger sus pequeñas propiedades y al mismo tiempo siguieron comprando más terrenos, aprovechándose de la pobreza de muchos campesinos que ya sin tierras se convertirían en ejidatarios. Estas solicitudes y los padrones que se levantaron en estos años indican que, a pesar del crecimiento de los latifundios durante el periodo porfirista, de su desintegración y la formación de núcleos ejidales en el valle de Teotihuacán, todavía había cientos de pequeños propietarios que estaban pagando sus contribuciones y trataron de proteger sus bienes ante los nuevos beneficiados de la reforma agraria cardenista.

El impuesto predial se siguió pagando al "administrador municipal de rentas" hasta mediados del siglo xx; por ejemplo, en abril de 1949, el tesorero municipal de Teotihuacán certificó que el difunto Cristóbal Aguilar, se encontraba registrado en el padrón de terrenos de común repartimiento del Barrio de Maquixco desde 1936 con la cantidad de 20 terrenos y los mismos terrenos aparecían a nombre de Modesto Fernández, quien seguramente los había comprado, y que ya estaban pagadas las contribuciones hasta el año 1948 por el mismo causante, con un valor total de 3985 pesos, y sólo debía "el presente año de 1949 ”. ${ }^{63}$ Las

de cuerpo riego $\$ 900.00$; humedad, 600.00 ; temporal, 300.00 ; delgadas de riego 500.00; delgadas de humedad 400.00; temporal 250.00; agostadero riego de $1^{\text {a }} 100.00$; pastales 75.00 y eriales 20.00 ".

${ }^{63}$ AHMTEO, Tesorería, El tesorero Carlos Ruiz Perdomo expide este 
transacciones por compraventa de terrenos durante las primeras décadas del siglo xx propiciaron que muchos comerciantes locales y foráneos adquirieran un número considerable de terrenos. Unos casos ilustran esta tendencia; la testamentaría y sucesores de Sixto Contreras, del barrio de Puxtla, manifestaron 47 terrenos valuados en 5530 pesos. $^{64}$ Otro caso de acumulación de este tipo de terrenos que llama la atención es el de María de los Ángeles Meneses, quien en 1936 era propietaria de 30 terrenos de común repartimiento en el barrio Evangelista y de 23 en Puxtla que sumaban 68 ha y tenían un valor de 7500 pesos. ${ }^{65}$ La familia Meneses, al igual que otras, habían acumulado propiedades desde la segunda mitad del siglo XIX y tenían "terrenos de común repartimiento" distribuidos en distintos lugares. ${ }^{66}$ El dueño del rancho La Ventilla, Rosalino Salcedo, tenía 25 ha; la mayoría de sus tierras eran de riego. En cambio, Carlos Beristáin era dueño del rancho Santa Ana y de 14

documento a solicitud de María Encarnación Redondo Vda. de Aguilar, Teotihuacán, 8 de abril de 1949.

${ }^{64}$ AHMTEO, Tierras, Cuaderno de propietarios de terrenos de común repartimiento de Puxtla y Evangelista, años de 1932-1936.

${ }^{65}$ AHMTEO, Tierras, Padrones de propietarios de terrenos en San Juan Teotihuacán, 1935 y 1936.

${ }^{66}$ AHMTEO, Tierras, En noviembre de 1906, José Meneses presentó una escritura otorgada a su favor en la que estaban inscritos 68 terrenos que le había vendido Antonio Aldama, entre ellos dos terrenos que son "propios del ayuntamiento" y afectos a 6\% anual valorizados uno en 195 pesos y otro en 260 pesos, y el resto, "considerando entre los demás con el carácter de los de común repartimiento”, es decir, por estos últimos se pagaría a la tesorería municipal "el once al millar”. Escrituras de terrenos de José Meneses, fondo Tierras, 1906. Ese mismo año, José Meneses, soltero de 35 años de edad y de oficio comerciante, compró otro terreno a doña Manuela Olivares por 30 pesos. 
terrenos, todos valuados en 8000 pesos. Asimismo, en 1939, en el pueblo de Maquixco, Agustín Ávila poseía 27 terrenos valuados en 8970 pesos y Benigno González tenía 12 terrenos cuyo costo era de 1000 pesos. ${ }^{67}$

Por tanto, cuando la hacienda desapareció, estos pequeños y medianos propietarios se convirtieron en los principales productores de cereales, hortalizas, alfalfa y leche para el mercado regional. Pero también hay que considerar que, al mismo tiempo, una parte notable de campesinos retuvieron sus pequeños predios que fluctuaban entre media hasta más de cinco ha. En el pueblo de Atlatango, pese a que en 1900 casi había sido cercado por las haciendas y tenía una población de 787 habitantes, ${ }^{68}$ de ellos, 232 estaban inscritos como causantes que estaban pagando su respectivo impuesto predial a la tesorería municipal. ${ }^{69}$ Varios de estos pequeños propietarios tenían más de cinco terrenos de cultivo, pero es probable que aquellos que tenían menos de una ha, o no tuvieran ninguna, se emplearan como trabajadores temporales en las haciendas cercanas. Incluso, el mismo pueblo de Atlatongo, después de la reforma agraria, tenía más tierras de pequeña propiedad que ejidos; en 1950 poseía 303 ha de propiedad privada y 262 de tierras ejidales. ${ }^{70}$ En este último año contaba con una población total de 1091 habitantes y 220 familias. En otras palabras, cada jefe de familia era

${ }^{67}$ AHMTEO, Tierras, Padrón de propietarios de tierras de común repartimiento,1930-1940.

${ }^{68}$ SAnders, “Tierra y agua”, p. 148.

${ }^{69}$ AHMTEO, Tesorería, Padrón de los causantes sujetos al pago de la contribución predial del once al millar sobre los terrenos de común repartimiento ubicado en el pueblo de Atlatongo, 1900.

70 SANDERs, "Tierra y agua”, p. 141. 
dueño ya sea de una o más parcelas de pequeña propiedad y, por si fuera poco, a veces podía contar con otra parcela ejidal.

De acuerdo con Margarita Nolasco, dentro de la propiedad individual del valle de Teotihuacán entre los años 1940 y 1960 encontramos tres modalidades según su tamaño; la gran propiedad mayor a 30 ha, mediana propiedad entre 5 y 30 y el minifundio menor a 5 ha. Los medianos y grandes propietarios utilizaban mano de obra local para el trabajo, invertían mayor capital, aplicaban tecnología como el uso de tractores y bombas eléctricas para extraer agua del subsuelo. Así mismo contaban con un sistema de riego y fertilizantes químicos para aumentar su producción. Sus principales cultivos eran alfalfa, maíz, cebada y hortalizas. Aparte tenían vacas lecheras y algunos negocios en el centro de Teotihuacán. Mientras los minifundistas y ejidatarios sembraban principalmente maíz y frijol, para completar su subsistencia se empleaban como trabajadores de rancheros prósperos o emigraban temporalmente para laborar como obreros y albañiles en la Ciudad de México. ${ }^{71}$

En lo que respecta al minifundio, muchas familias tenían entre uno y cuatro predios, pero en términos generales difícilmente alcanzaban las cinco ha de superficie, por lo tanto, los hijos mayores de la familia que no heredaban la tierra buscaban otras actividades económicas no agrícolas. Si observamos el escalón más bajo de la pirámide social, a mediados del siglo xx, más de la mitad de las familias del municipio poseía un predio, ya sea bajo el régimen ejidal o de propiedad privada, mientras que otros tantos, poseían entre dos y cinco predios.

${ }^{71}$ Nolasco, "La tenencia de la tierra", p. 75. 
Muchos de estos minifundistas eran usuarios de las aguas de los manantiales de San Juan Teotihuacán. Por ejemplo, en la cabecera y sus barrios se anotaron muchos pequeños propietarios que utilizaban las aguas para regar sus terrenos; en Tepexpan había 63; San Pedro Tepetitlán 24; San Bartolo y Barrio de San Juanico 84; Santa Catarina 141; El Calvario 50; Xometla 56; Santa María 27. Sin embargo, había otros que quedaron fuera del sistema, porque el agua no alcanzaba o por la misma situación geográfica de los predios. Veamos un caso: pese a que el pueblo de Atlatongo se encontraba casi en el punto central del sistema de riego, no todas sus tierras eran irrigadas; según el secretario ejidal sólo se regaban 132 ha ejidales y 103 de pequeña propiedad, en cambio quedaban sin riego 130 ha ejidales de tierras cerriles y 200 de pequeña propiedad. ${ }^{72}$

Por otra parte, notamos que había grandes diferencias entre los pequeños propietarios del valle de Teotihuacán; algunos campesinos solamente tenían una parcela y otros eran dueños de más de 15; de igual modo variaba la superficie de los predios. Mientras la mayoría de los pequeños propietarios de Tepexpan tenían una parcela de cultivo, había quienes poseían más de seis; en 1929 la superficie se midió por cuartillos dando un total de 749 cuartillos por los 63 propietarios, pero sólo 3 de ellos tenían en su poder 151 cuartillos, es decir, casi $20 \%$. Lo mismo sucedía en otros grupos de pequeños propietarios; en el Barrio de San Pedro Tepetitlán don José Rincón tenía 16 predios y Emidio Juárez tenía 13 terrenos de cultivo. Algo similar detectamos en Xometla, donde había pequeños propietarios que tenían más de 9 terrenos de cultivo; de los 56 propietarios que se

72 Sanders, “Tierra y agua”, p. 141. 
anotaron, solamente 6 campesinos acumulaban 76 terrenos de diferente tamaño y calidad, como se aprecia en el cuadro 5 .

\section{Cuadro 5}

PEQUEÑOS PROPIETARIOS DE XOMETLA QUE TENÍAN MÁS

DE 9 TERRENOS

\begin{tabular}{|l|c|c|}
\hline Nombre del propietario & $\begin{array}{c}\text { Cantidad de terrenos } \\
\text { que poseía cada uno }\end{array}$ & $\begin{array}{c}\text { Superficie } \\
\text { en cuartillos }\end{array}$ \\
\hline Enrique Contreras & 18 & $1381 / 2$ \\
\hline José María Cruz & 14 & $1091 / 4$ \\
\hline Reyes Juárez & 11 & 108 \\
\hline Doroteo Contreras & 9 & $901 / 2$ \\
\hline Urbano Rosas & 14 & 55 \\
\hline Carmelo Rosas & 10 & 60 \\
\hline & 76 & \\
\hline
\end{tabular}

Fuente: AHA, Aprovechamientos superficiales, c. 416, exp. 7740, ff. $52-115$.

Carmelo Rosas también era dueño de seis parcelas en Santa María, pero del total de 551 cuartillos que cultivaban los 27 propietarios de ese barrio, Rosas cultivaba 111 cuartillos, es decir, acumulaba $20 \%$ de la superficie de tierras de riego. ${ }^{73}$ En otras palabras, con estas listas de pequeños propietarios se infieren no sólo las formas de explotación y producción sino también las diferencias socioeconómicas que existían en casi todos los pueblos del valle de Teotihuacán. Un caso que llama la atención y que parece más equitativo es el de Santa Catarina, pues había 141 pequeños propietarios, cada uno con un terreno, es decir, se anotaron 141 terrenos; sin embargo, no todos eran del mismo tamaño

73 AHA, Aprovechamientos superficiales, c. 416, exp. 7740, ff. 52-115. 
pues la superficie irrigada para cada uno variaba entre medio cuartillo hasta 12.

A mediados del siglo xx, aproximadamente $50 \%$ de las familias del municipio eran dueñas de un terreno de cultivo, ya sea como ejido o como pequeña propiedad, pero en general su producción era para el autoconsumo; las familias que tenían entre 5 y 10 ha destinaban una parte para la venta y otra para la subsistencia. En cambio, los medianos y grandes propietarios que poseían más de 30 ha destinaban su producción al mercado.

Según el censo agrícola ganadero realizado en 1950, en el municipio de San Juan Teotihuacán existían 58 predios mayores de 5 ha, lo que daba un total de 3505 ha y 29 áreas. Asimismo se contabilizaron 709 predios menores de 5 ha que sumaban una superficie de 1115 ha, 38 áreas y 77 centíareas ha. ${ }^{74}$ En cambio, diez años después, Margarita Nolasco registró no sólo la distribución de la pequeña propiedad sino también el número de ejidatarios que existían en el municipio de San Juan Teotihuacán, como vemos en el cuadro 6.

\section{Cuadro 6}

EJIDATARIOS Y PEQUEÑOS PROPIETARIOS EN 1960

\begin{tabular}{|l|r|}
\hline Tipo de propietarios & Total \\
\hline Propietarios con más de $30 \mathrm{ha}$ & 28 \\
\hline Medianos propietarios que tenían entre 5 y 30 ha & 44 \\
\hline Pequeños propietarios con menos de 5 ha & 881 \\
\hline Total de pequeños propietarios & 953 \\
\hline Ejidatarios con menos de $3 \mathrm{ha}$ & 1262 \\
\hline
\end{tabular}

Fuente: Nolasco, “La tenencia de la tierra”, p. 14.

74 AHMTEO, Tierras, Censo agrícola ganadero, Teotihuacán, 16 de junio de 1950. 
En un periodo de sólo 10 años habían aumentado los propietarios particulares, probablemente por la compra y división de tierras; así, en lugar de 58 para 1960 tenemos 72 propietarios con más de 5 ha, pero también habían aumentado los que poseían menos de 5 ha; de 709 pasaron a ser 881. Pese a que había 1262 ejidatarios y sólo 953 pequeños propietarios, la pequeña y mediana propiedad privada no sólo iba en aumento sino que además era de donde se obtenía la producción más exitosa para abastecer el mercado local y exportar los excedentes a la Ciudad de México, lo que corrobora que durante la segunda mitad del siglo XIX muchos vecinos de los pueblos se adjudicaron sus tierras de común repartimiento y, contrario a lo que señaló Lucio Mendieta, la pequeña propiedad no desapareció, por el contrario, se mantuvo vigorosa a pesar de la reforma agraria.

\section{CONSIDERACIONES FINALES}

Aunque la ley general de desamortización de 1856 en términos legales cambio el sistema de propiedad colectiva por un sistema de propiedad privada, en la práctica el proceso fue lento, confuso y complicado, como hemos visto en el caso de los pueblos y barrios de San Juan Teotihuacán; la mayoría de los campesinos comuneros no se resistieron a la privatización y paulatinamente fueron adjudicándose sus respectivas parcelas que poseían en usufructo, pero a cambio tuvieron que pagar un censo a la tesorería municipal por sus "tierras de común repartimiento", lo que a la larga resultó en un impuesto predial que benefició principalmente a la tesorería municipal.

La liberación de la propiedad corporativa y el desarrollo económico porfirista que se manifestó con el paso del 
ferrocarril por Teotihuacán incidió en el crecimiento del comercio y generó una extensa compraventa de tierras adjudicadas que pasaron no sólo a manos de hacendados, sino también a poder de otros campesinos, comerciantes, rancheros y caciques locales.

En términos generales detectamos que la pequeña propiedad privada persistió a lo largo de estos años, de modo que desde 1870 hasta más allá de la década de 1950 se suscitaron una enorme cantidad de compraventas de terrenos llamados de común repartimiento, pero en dos momentos significativos con su particular régimen de propiedad; el primero, caracterizado por la desamortización de las tierras comunales que se inicia con la Ley Lerdo de 1856, donde destacan las ventas de pequeños lotes que los primeros adjudicatarios hicieron a caciques y comerciantes locales, pero principalmente por la acumulación de la propiedad por parte de las latifundios de la región, a tal grado que para principios del siglo $\mathrm{xx}$, una parte considerable del territorio municipal estaba en poder de las haciendas y en menor medida persistían rancheros y pequeños propietarios. Un segundo momento se detecta con la ley de 6 de enero de 1915 y la Constitución de 1917 que propugnaban por la restitución de tierras comunales y la dotación de ejidos, es decir, por una etapa de amortización de la denominada propiedad social, pero al mismo tiempo, se conservó la pequeña propiedad privada y continuó la reventa de este tipo de terrenos. Y esta aparente contradicción explica por qué en un país de corte capitalista los pequeños propietarios no fueron afectados, por el contrario, tanto el gobierno de Obregón como el de Calles eran partidarios de este tipo de propiedad, pues desde su óptica norteña, era la forma más adecuada para 
elevar la producción agrícola, de tal modo que los pequeños propietarios continuaron manteniendo sus propiedades y pagando sus contribuciones correspondientes, y por tanto, tuvieron el derecho de venderlas, traspasarlas y heredarlas según sus intereses. Pero, por otro lado, en el corto y largo plazo se generaron constantes conflictos entre los actores sociales: exhacendados, ejidatarios, pueblos y pequeños propietarios que se disputaron los recursos de tierra y aguas en el valle de Teotihuacán y utilizaron la legislación según sus intereses.

En suma, pese al crecimiento de las haciendas durante el porfiriato, la lucha revolucionaria y posteriormente el reparto agrario, podemos concluir que la pequeña propiedad persistió bajo la nomenclatura de terrenos de común repartimiento y hasta se fortaleció en un mundo de ejidatarios. A mediados del siglo xx los pequeños propietarios fueron los principales productores para el mercado regional pues poseían las parcelas más grandes y fértiles de la región. Desde esa perspectiva se debe entender el fracaso del ejido en el valle de Teotihuacán, cuya extensión por ejidatario era menor a 2 ha y por lo mismo, su producción fue destinada casi a la subsistencia, en cambio, los pequeños y medianos productores cuyas parcelas iban de 1 a 60 ha se convirtieron en los principales productores de hortalizas, alfalfa, leche, nopal, pulque y tunas para el mercado de la Ciudad de México. Pero esa es otra historia. 


\section{SIGLAS Y REFERENCIAS}

AGA Archivo General Agrario, Ciudad de México.

AHA Archivo Histórico del Agua, Ciudad de México.

AHMTEO Archivo Histórico Municipal Teotihuacán, San Juan Teotihuacán, Estado de México.

\section{Birrichaga Garrida, Diana}

"Administración de tierras y bienes comunales. Política, organización territorial y comunidad de los pueblos de Texcoco, 1812-1857", tesis de doctorado en historia, México, El Colegio de México, 2003.

"Imaginar el poder local; los debates del Congreso Constituyente del Estado de México (1824)”, en Salinas, Birrichaga y Escobar Ohmstede (coords.), 2011, pp. 195-224.

Camacho Pichardo, Gloria

"De la desamortización a la reforma agraria. Los pueblos del sur del valle de Toluca, 1856-1930", tesis de doctorado en historia, México, El Colegio de México, 2006.

\section{Colección}

Colección de decretos del Congreso extraordinario del Estado libre y soberano de México, que funcionó en la segunda época de la federación, Toluca, México, Tipografía de J. Quijano, 1850.

Colección de Decretos del segundo Congreso constitucional del Estado Libre y Soberano de México, que funcionó en la segunda época de la federación en el bienio corrido de 2 de marzo de 1851 a igual fecha de 1853, Toluca, Tipografía del Instituto Literario.

Colección de decretos expedidos por el décimo séptimo Congreso Constitucional y por el ejecutivo del Estado libre y soberano de México en el periodo corrido de 2 de marzo de 1897 a 2 de marzo de 1899, t. XXV, Toluca, Oficina Tipográfica del Gobierno, 1897. 
Colección de Leyes, decretos, reglamentos, circulares, órdenes y acuerdos relativos a la desamortización de los bienes de corporaciones civiles y religiosas y a la nacionalización de los que administraron las últimas, México, Tipografía de la Oficina Impresora de Estampillas.

Congost, Rosa

Tierras, leyes, historia. Estudios sobre la gran obra de la propiedad, Barcelona, Crítica, 2007.

Escalante Gonzalbo, Fernando

"El lenguaje del artículo 27 constitucional”, en Kourí (coord.), 2009, pp. 229-252.

Escobar Ohmstede, Antonio

"Los condueñazgos indígenas en las Huastecas hidalguense y veracruzana: ¿defensa del espacio comunal?”, en Escobar OHMSTEDe (coord.), 1993, pp. 171-188.

Escobar Ohmstede, Antonio (coord.)

Indio, nación y comunidad en el México del siglo XIX, México, Centro de Estudios Mexicanos y Centroamericanos, Centro de Investigaciones y Estudios Superiores en Antropología Social, 1993.

Fabila, Manuel

Cinco siglos de legislación agraria en México, 1493-1940, México, Procuraduría Agraria, 2005, t. I.

FALCón, Romana

"Desamortización a ras de suelo, ¿el lado oculto del despojo?: México en la segunda mitad del xix", en Ponce y Pérez (coords.), 2009, pp. 59-85.

Gamio, Manuel

La población del valle de Teotihuacán, México, Instituto $\mathrm{Na}-$ cional Indigenista, 1979, 4 tomos. 
García Martínez, Bernardo (coord.)

Lecturas de historia mexicana, 2, México, El Colegio de México, 1991.

Iracheta Cenecorta, María del Pilar y Diana Birrichaga (comps.) A la sombra de la primera república federal. El Estado de México, 1824-1835, Toluca, Estado de México, El Colegio Mexiquense, 1999.

Knowlton, Robert

"La individualización de la propiedad corporativa civil en el siglo XiX”, en García MARTíneZ (coord.), 1991, pp. 181-218.

Kourí, Emilio

"Los pueblos y sus tierras en el México porfiriano, un legado inexplorado de Andrés Molina Enríquez", en Kourí (coord.), 2009, pp. 253-330.

Un pueblo dividido. Comercio, propiedad y comunidad en $\mathrm{Pa}$ pantla México, México, Fondo de Cultura Económica, 2013.

KOuRí, Emilio (coord.)

En busca de Molina Enríquez. Cien años de Los grandes problemas nacionales, México, El Colegio de México, Centro Katz-The University of Chicago, 2009.

Macpherson, Crawford B. (ed.)

Property. Mainstream and Critical-Positions, Oxford, Basil Blackwell, 1978.

Marichal, Carlos, Manuel Miño, Paolo Riguzzi

Historia de la Hacienda Pública del Estado de México, vol. I, El primer siglo de la Hacienda Pública en el Estado de México, 1824-1923, México, El Colegio Mexiquense, Gobierno del Estado de México, 1994. 
Marino, Daniela

"La desamortización de las tierras de los pueblos (centro de México, siglo xIx). Balance historiográfico y fuentes para su estudio", en América Latina en la historia económica. Boletin de Fuentes, 16 (2001), pp. 33-43.

"La modernidad a juicio: los pueblos de Huixquilucan en la transición jurídica (Estado de México, 1856-1911)”, tesis de doctorado en historia, México, El Colegio de México, 2006.

Mendieta Núñez, Lucio

El problema agrario de México, México Porrúa, 1966.

Mendoza García, Edgar J.

"Oposición al reparto agrario. Los hacendados de Otumba y Teotihuacán”, en Contribuciones desde Coatepec, 19 (jul.dic. 2010), pp. 61-88.

Municipios, cofradias y tierras comunales. Los pueblos chocholtecos de Oaxaca en el siglo XIX, México, Centro de Investigaciones y Estudios Superiores en Antropología Social, Universidad "Benito Juárez de Oaxaca”, Universidad Autónoma Metropolitana-Azcapotzalco, 2011.

"Los municipios de San Gabriel Chilac y San Juan Teotihuacán ante la federalización de las aguas, 1880-1960", en Relaciones, xxxiv: 136 (otoño 2013), pp. 359-397.

Menegus, Margarita

"Ocoyoacac: una comunidad agraria en el siglo XIX", en MENEGUS (comp.), 1995, pp. 144-189.

"La desamortización de los bienes comunales y municipales en el valle de Toluca (1800-1854)", en Iracheta Cenecorta y BirRichaga (comps.), 1999, pp. 279-297.

La Mixteca Baja entre la revolución y la reforma. Cacicazgo, territorialidad y gobierno, siglos XVIII y XIX, Oaxaca, Universidad Autónoma "Benito Juárez de Oaxaca", Universidad Autónoma Metropolitana, Gobierno del Estado de Oaxaca, 2009. 
Menegus, Margarita (coord.)

Problemas agrarios y propiedad en México. Siglos XVIII y XIX, México, El Colegio de México, 1995.

Merino, Mauricio

Gobierno local, poder nacional. La contienda por la formación del Estado mexicano, México, El Colegio de México, 1998.

Merino, Mauricio (comp.)

En busca de la democracia municipal. La participación ciudadana en el gobierno local mexicano, México, El Colegio de México, 1994.

Meyer Lorenzo

"El municipio mexicano al final del siglo xIx. Historia, obstáculos y posibilidades", en Merino (comp.), 1994, pp. 231-252.

Molina Enríquez, Andrés

Breve estudio para la determinación jurídica de los bienes municipales llamados de común repartimiento, Toluca, Estado de México, Gobierno del Estado de México, 1970.

Nolasco, Margarita

"La tenencia de la tierra en el municipio de San Juan Teotihuacán, Edo. de México", en Acta Anthropologica, época 2, II: 3 (1962).

Ortiz Yam, Inés

De milperos a benequeneros en Yucatán, 1870-1937, México, El Colegio de México, 2013.

Ponce, María Eugenia y Laura Pérez (coords.) El oficio de una vida: Raymond Buve, un historiador mexicanista, México, Universidad Iberoamericana, 2009. 
Riguzzi, Paolo

"El camino hacia la modernidad: la hacienda pública del Estado de México, 1870-1923”, en Marichal, Miño, Riguzzi, 1994, vol. I.

Los municipios en la formación del Estado de México, 18241846, México, El Colegio Mexiquense, 2001.

"Desamortización en Acambay, Estado de México. Proceso articulador de conflictos por la tierra”, en SERrano, Escobar Ohmstede y Sánchez (coords.), 2009, pp. 143-176.

Salinas, María del Carmen, Diana Birrichaga y Antonio Escobar OHMSTEde (coords.)

Poder y gobierno local en México 1808-1857, México, El Colegio de Michoacán, El Colegio Mexiquense, Universidad Autónoma del Estado de Morelos, 2011.

SÁnchez Rodríguez, Martín

"El mejor de los títulos." Riego, organización y administración de recursos hidráulicos en el Bajío mexicano, Zamora, Mich., El Colegio de Michoacán, 2005.

SÁnchez Silva, Carlos (coord.)

La desamortización civil en Oaxaca, México, Universidad Autónoma Benito Juárez de Oaxaca, Universidad Autónoma Metropolitana, 2007.

SANDERs, William T.

"Tierra y Agua. A Study of Ecological Factors in the Development of Mesoamerica Civilizations", tesis de doctorado en antropología, Boston, University of Harvard, 1957.

Serrano, Jesús, Antonio Escobar Ohmstede y Martín Sánchez (coords.)

Negociaciones, acuerdos y conflictos en México, siglos XIX y XX. Agua y tierra, México, Centro de Investigaciones y Estudios Superiores en Antropología Social, El Colegio de Michoacán, Universidad Autónoma de Aguascalientes, 2009. 
VAlladares, Laura

Cuando el agua se esfumó. Cambio y continuidades en los usos sociales del agua en Morelos, 1880-1940, México, Universidad Nacional Autónoma de México, 2003.

Velasco Toro, José y Luis García (coords.)

Perfiles de la desamortización civil en Veracruz: siglo XIX, Xalapa, Editora del Gobierno del Estado de Veracruz, 2009.

Velasco Toro, José, Luis García y Olivia Domínguez (coords.)

La ley de 6 de enero de 1915. Nueve estudios en el centenario de su promulgación, Veracruz, Gobierno del Estado de Veracruz, 2015. 
